RELACult - Revista Latino-Americana de Estudos em Cultura e Sociedade e-ISSN 2016/Atual: 2525-7870 | e-ISSN 2015/2016: 2447-018X

\title{
Fotografia e Memória na série Nazaré do Mocajuba: Uma breve introdução
}

\author{
Fotografía y memoria en la serie Nazaré do Mocajuba: Una breve \\ introduccion
}

\section{Photography and memory in the serie Nazaré do Mocajuba: A brief introduction}

\section{Maria Clara de Matos Coelho ${ }^{1}$}

\begin{abstract}
Resumo
O presente trabalho visa apresentar uma introdução da pesquisa realizada sobre as relações entre fotografia e memória, tendo como objeto de estudo a série Nazaré do Mocajuba. Para isso utilizou-se uma metodologia qualitativa, com análise de dados como entrevistas, fotografias e gravações de palestras. A partir da análise e interpretação dos dados, considera-se que há relações entre fotografia e memória na série, presentes desde o momento da captura das imagens ao uso das fotografias.
\end{abstract}

Palavras-Chave: Fotografia; Memória; Nazaré do Mocajuba; Alexandre Sequeira.

\section{Resumen}

Lo presente trabajo pretende presentar una introducción de la investigación realizada sobre las relaciones entre fotografía y memoria, utilizando la serie Nazaré do Mocajuba como objeto de estudio. Para eso, se utilizó una metodología cualitativa, con análisis de datos como entrevistas, fotografías y grabaciones de conferencias. A partir del análisis y interpretación de los datos, se considera que existen relaciones entre fotografía y memoria en la serie, presentes desde lo momento de la captura de imagen a los usos de la fotografía.

Palabras claves: Fotografía; Memoria; Nazaré do Mocajuba; Alexandre Sequeira

\begin{abstract}
The present work aims to introduce the research about the relations between photography and memory, taking the series Nazare do Mocajuba as object of study. In order to do that it was applied a qualitative methodology, with data analysis such as interviews, photographies, and recordings of conferences. From the data analysis and interpretation, believed there to be relations between photography and memory in the series, present from the moment of the capture of the image to the use of the photos.
\end{abstract}

Keywords: Photography; Memory; Nazaré do Mocajuba; Alexandre Sequeira

\footnotetext{
${ }^{1}$ Bacharel em Produção Cultural; Instituto Federal de Educação, Ciência e Tecnologia do Rio de Janeiro; Nilópolis, Rio de Janeiro, Brasil; mclaramatos@yahoo.com.br
} 


\section{Introdução}

Vivemos em uma sociedade cercada por imagens. Dentro das residências, nas ruas, nos espaços de convivência, não conseguimos nos distanciar delas. Estão presentes nos televisores, nos outdoors, nas bancas de jornais, nas vitrines e nos celulares. Este, inclusive, é um dos mais comuns geradores de boa parte das imagens consumidas. Com a democratização de acesso proporcionada pelo avanço da tecnologia, somos produtores ativos de fotografias.

A fotografia deixou de ser algo restrito a pessoas com maior poder aquisitivo, detentoras da possibilidade de comprar equipamentos caros, e tornou-se acessível com as câmeras digitais e os aparelhos celulares. Hoje em dia é difícil encontrar telefones que não possuam ao menos uma câmera integrada.

Nossa relação com a fotografia no dia-a-dia vem se tornando cada vez mais direta e intensa. Fotografamos a nós mesmos e aos outros. Fotografamos os mais diversos assuntos e motivos. Fotografamos diariamente. Fotografamos para registrar, guardar e lembrar. Fotografamos para mostrar. Fotografamos para nos afirmar.

Ao mesmo tempo que o avanço tecnológico contribuiu para o aumento da produção de imagens, de certa forma, proporcionou uma nova relação com a mesma. Antes a fotografia era mais difícil de ser obtida. Realizada através de câmeras analógicas que dispunham de filmes com limitadas poses, cada enquadramento era pensado ao máximo para que o resultado, o qual só seria conhecido após a revelação do filme, fosse o melhor possível. Atualmente, a fotografia é realizada em poucos segundos através de um clique.

Podemos fotografar mais, escolher mais e excluir mais. A revelação já não é um serviço tão requisitado, a fotografia impressa não está presente em grande quantidade nos lares como anteriormente. O armazenamento e a visualização agora são virtuais. Observamos as imagens nos computadores, tablets, celulares e demais dispositivos eletrônicos. E, ao mesmo tempo em que esse tipo de armazenamento facilita o manuseio e o compartilhamento, é também suscetível a perdas.

Os antigos álbuns de fotografia, não tão presentes como antigamente, deram lugar aos álbuns virtuais, publicados em redes sociais. O que era restrito a família e a poucos amigos íntimos, cede lugar a uma exposição pública, muitas vezes de longo alcance. Junto a isso, a seletividade do que desejamos mostrar aumentou. As fotografias expostas irão intervir na forma como os outros nos veem e estão diretamente ligadas as mensagens que queremos transmitir. E afinal, o que queremos guardar e exibir para nós e para a sociedade? Que memória queremos construir? 
Segundo Le Goff (1990, p. 466) a fotografia é uma das manifestações mais importantes da memória coletiva que surgiram entre os séculos XIX e XX. Para o autor, a fotografia multiplica a memória e a democratiza, dessa forma revoluciona-a ao possibilitar "guardar a memória do tempo e da evolução cronológica" (LE GOFF, 1990, p. 466). A fotografia possui os mais diferentes usos e, enquanto produção artística, também contribui no processo de construção de memória. Assim como acontece na série Nazaré do Mocajuba, do artista visual Alexandre Sequeira, realizada entre abril de 2004 e dezembro 2005 na vila Nazaré do Mocajuba, no estado do Pará. A série, a qual possui a linguagem fotográfica em seu processo, possibilita diversas discussões tanto a partir de um dos seus principais formatos de apresentação, os tecidos e fotografias, quanto pelo o que foi suscitado no decorrer de sua criação e produção.

Desta forma, o objetivo deste trabalho é apresentar uma introdução da pesquisa realizada sobre as relações entre fotografia e memória, tendo como objeto de estudo a série Nazaré do Mocajuba e as possíveis relações entre fotografia e memória presentes nela. A pesquisa foi orientada pela professora Dra. Fernanda Delvalhas Piccolo e resultou na realização da monografia "Fotografia e memória: Um estudo sobre a série Nazaré do Mocajuba, de Alexandre Sequeira" como trabalho de conclusão de curso no Bacharelado em Produção Cultural do Instituto Federal de Educação, Ciência e Tecnologia do Rio de Janeiro.

A metodologia utilizada foi qualitativa, com análise de dados como entrevista realizada por mim com o artista, entrevistas realizadas por outras pessoas, gravações de palestras oferecidas por Alexandre, fotografias da série e de seu processo, presentes no Portfólio do artista, cedido pelo mesmo e o relatório final da pesquisa desenvolvida por Alexandre. Para analisar e interpretar os dados utilizou-se autores que trabalham com fotografia, como Barthes (1984) e Sontag (2004), e memória, como Halbwachs (1990) e Nora (1993).

\section{Fotografia e arte}

Nesse segundo momento trato brevemente de como a fotografia passou a ser vista como arte, para posteriormente apresentar e analisar a obra de Alexandre Sequeira, pensando nas relações entre fotografia e memória.

No período de seu surgimento, a fotografia não era legitimada enquanto arte, pois acreditava-se que seu processo era estritamente mecânico, que a imagem era uma produção apenas do equipamento fotográfico, não existindo interferência humana. Assim, a fotografia 

e-ISSN 2016/Atual: 2525-7870 | e-ISSN 2015/2016: 2447-018X

difere-se das linguagens artísticas anteriores, nas quais a mão do homem era fundamental em sua produção, como a pintura, desenho e gravura.

Há também na década de 1880, o surgimento de equipamentos mais acessíveis, possibilitando os usos sociais da fotografia e consequentemente sua democratização. Em 1884 George Eastman cria os filmes fotográficos flexíveis e em 1888 a Kodak nº 1 , primeira câmera portátil. Mais simples e prática, a Kodak usou o slogan "Aperte o botão que nós fazemos o resto”. Conforme afirma Brasil (2012, p. 866), “o público em geral não compraria mais as fotografias e sim as produziria".

A reação contra a massificação fortaleceu a visão da fotografia como arte. $O$ pictorialismo foi um movimento que colaborou nesse sentido, como aponta Rouillé:

\footnotetext{
Para eles, trata-se igualmente de tudo fazer contra as supostas causas da decadência da fotografia: contra a industrialização e a democratização, contra a padronização e a vulgarização, contra a mercadoria. Tudo isso com a finalidade de reavaliar a fotografia, de passá-la do domínio das artes mecânicas para o domínio da arte como um todo (ROUILLÉ, 2009, p. 253).
}

O movimento, que possui Alfred Stieglitz como um de seus principais representantes, visava um olhar mais autoral em relação à realidade fotografada, aproximando-a das belasartes e fugindo de uma mecanização ou reprodução do real. Assim, "por meio de técnicas apuradas, como por exemplo a goma bicromatada, que aproximavam a imagem fotográfica da gravura, da aquarela e da própria pintura, estes fotógrafos devolveram à fotografia o caráter de unicidade" (TAKAMI, 2006, p. 539).

Ao longo dos anos, a fotografia artística vem se transformando e reinventando, afastando-se dos padrões clássicos do fazer fotográfico. A fotografia contemporânea é híbrida e múltipla, passível de ser trabalhada em diferentes suportes e a partir de diversas técnicas, dialoga com outras linguagens em uma mesma obra, é expandida. Como afirma Fernandes Junior (2006, p. 10),

da mesma maneira que percebemos o ir além, o ultrapassar de todos os limites, a contaminação das técnicas, o hibridismo dos suportes, verificamos o quanto é difícil e impreciso articular uma nomenclatura para a produção contemporânea.

No mesmo artigo, Fernandes Junior (2006), trabalha o conceito de fotografia expandida. Por ele entende-se a produção artística que vai além do foco no produto final, que enfatiza o processo de criação e seus procedimentos, sendo uma produção desprendida dos padrões clássicos. Essas novas possibilidades permitem uma maior liberdade aos artistas para 
pensar e criar. Indo ao encontro a essa produção contemporânea, expandida e híbrida, deparase com a série Nazaré do Mocajuba e outros trabalhos do artista visual Alexandre Sequeira.

\subsection{Série Nazaré do Mocajuba}

O artista, nascido em Belém, capital do estado do Pará, em 1961, é formado em arquitetura pela Universidade Federal do Pará (UFPA). Após a conclusão da graduação, mudou-se para São Paulo, onde trabalhou como designer gráfico. Nesse momento começou a ter contato mais direto com a fotografia, porém ainda aplicada a sua área de atuação. Foi quando retornou a Belém no início dos anos 90 e passou a frequentar a associação FotoAtiva, onde teve a oportunidade de aproximar-se da fotografia em uma perspectiva mais autoral. Posteriormente ingressou no campo educacional, lecionando na graduação em Artes Visuais da Universidade da Amazônia (UNAMA) e depois na UFPA, onde trabalha até hoje.

Alexandre Sequeira, que possui gosto por viagens, reconhece seu espírito meio andarilho. Machado (2011, p. 37), define Alexandre como "viajeiro laboral". O termo, inspirado na obra $O$ Turista Aprendiz, de Mário de Andrade, é referência ao artista porque ele "sempre atribui às suas expedições o caráter de investigações culturais, fazendo-se acompanhar por sua câmera fotográfica, com o objetivo de reunir material e registros que permitiam a expansão de caminho" (MACHADO, 2011, p. 37).

Um dado importante na obra de Alexandre é o encontro. O encontro com as pessoas e as relações por ele suscitadas. Por isso sua obra, em geral, se associa ao conceito de arte relacional, o qual, segundo Borriaud (2009, p. 151), refere-se ao "conjunto de práticas artísticas que tomam como ponto de partida teórico e prático o grupo das relações humanas e seu contexto social, em vez de um espaço autônomo e privativo". Para Sequeira (2010, p. 61) os encontros permitem o desenvolvimento de "pensamentos singulares e pontos de indução de ações de caráter artístico". Considerando os conceitos de fotografia expandida e arte relacional, chega-se a série Nazaré do Mocajuba, de Alexandre Sequeira.

A série foi realizada na pequena vila de pescadores Nazaré do Mocajuba, localizada no município Curuçá, a aproximadamente 150 km de Belém. Como descreve Sobral (2004),

chega-se a Nazaré do Mocajuba percorrendo um estreito caminho de terra de, aproximadamente, nove quilômetros, contados a partir da estrada que liga Castanhal à região litorânea de Marapanim e Marudá, à altura do km 42 - nove quilômetros que representam, para a comunidade, um enorme isolamento social e econômico. Seus limites são os roçados, a mata em torno e o rio Mocajuba à frente, com sua 
RELACult - Revista Latino-Americana de Estudos em Cultura e Sociedade

Revista Latinoamericana de Estudios en Cultura y Sociedad | Latin American Journal of Studies in Culture and Society

V. 03, ed. especial, ago., 2017, p. 65-79| relacult.claec.org e-ISSN 2016/Atual: 2525-7870 | e-ISSN 2015/2016: 2447-018X

densa vegetação de mangue. As atividades produtivas do lugar se restringem a culturas de subsistência: plantio da mandioca, farinha, pesca e extração do caranguejo; além de um pequeno comércio de bebidas e alimentos, ponto de encontro dos nativos. [...] As casas, a maioria de barro, distribuem-se no raio de alguns metros da rua principal, via de terra batida paralela ao rio. [...] No centro, destaca-se uma pequena igreja branca e singela. Sobre o rio avança o trapiche de madeira que serve à vila como porto e, para nós visitantes, de mirante, onde podemos nos debruçar, no fim da tarde, sobre os belos jogos de espelho das águas do Mocajuba.

Alexandre Sequeira já conhecia a vila, mas foi em 2004, ao ser contemplado pela bolsa de Pesquisa, Experimentação e Criação Artística do Instituto de Artes do Pará (IAP) que retornou a vila com o objetivo de "desenvolver uma poética visual, tendo a fotografia como linguagem e a pequena vila de pescadores de Nazaré do Mocajuba como fonte inspiradora". (SEQUEIRA, 2005, p. 1)

E assim iniciou-se o estreitamento da relação entre Alexandre e os moradores de Mocajuba. Acompanhado de sua câmera fotográfica, passou a frequentar mais a vila e a fotografar principalmente a geografia local (Fotografia 1).

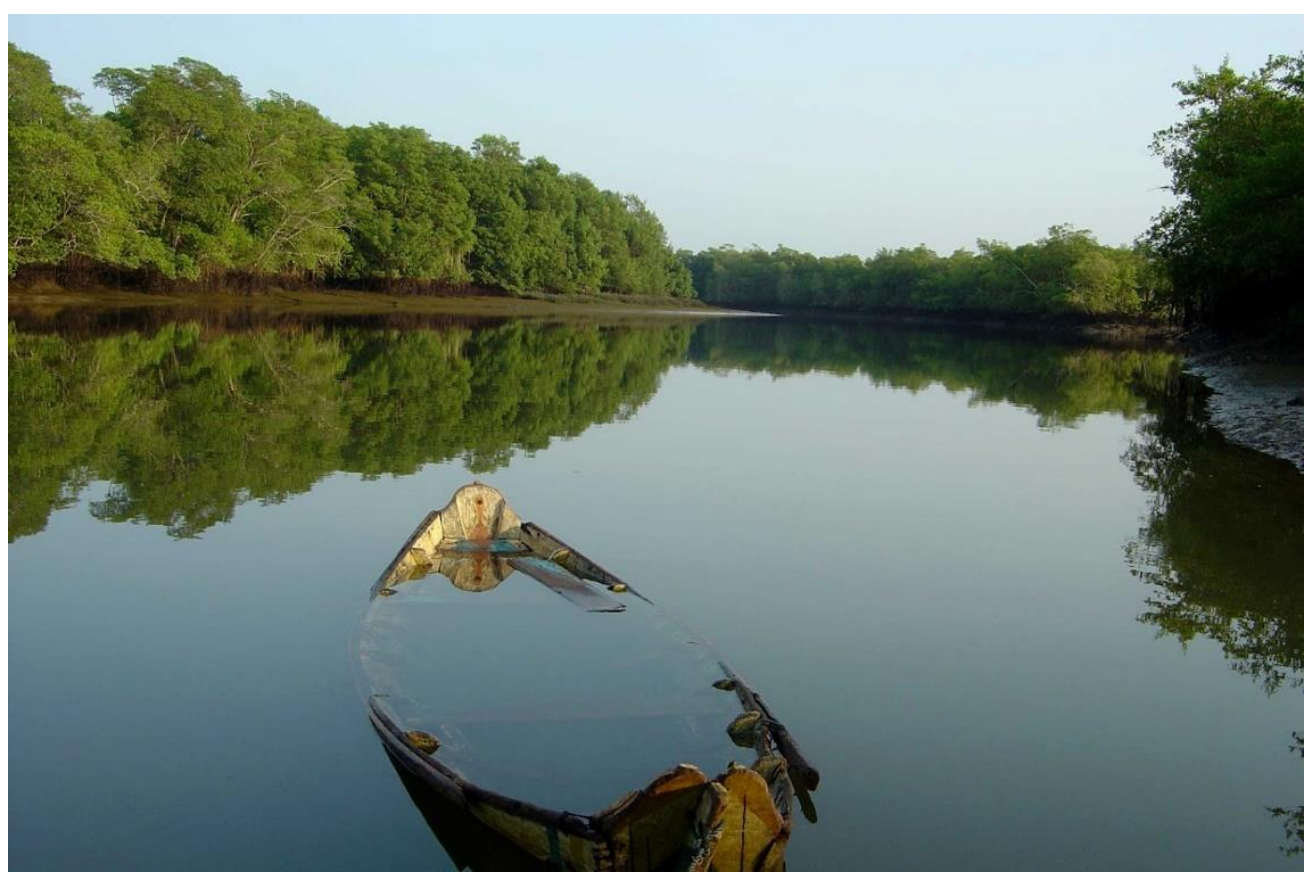

Fotografia 1: Alexandre registra a geografia local

Fonte: Portfólio Alexandre Sequeira

Devido ao fato do artista estar sempre de posse de sua câmera fotográfica, Alexandre me relatou em entrevista que começou a perceber como a fotografia era um motivo para as pessoas se aproximarem dele. E, independentemente de onde estivesse, as conversas iniciavam movidas por assuntos que diziam respeito a fotografia. Esse fato chamou sua 
RELACult - Revista Latino-Americana de Estudos em Cultura e Sociedade e-ISSN 2016/Atual: 2525-7870 | e-ISSN 2015/2016: 2447-018X

atenção e despertou seu interesse. A fotografia passou então a ser um instrumento de aproximação entre o artista e os moradores da vila.

Em um dado momento uma moradora solicitou a Alexandre uma fotografia para documento. Depois dessa solicitação, outras foram sendo realizadas e com o tempo, ele passou a condição de retratista do lugar. Segundo me afirmou em entrevista, "era retratista em que eu não decidia nada, eu simplesmente aguardava as solicitações e conforme vinham eu as executava". As demandas costumavam ser de fotografias para documento, o clássico formato 3x4 (Fotografia 2), mas havia pedidos também para fotografar famílias, entes que estavam idosos e eventos religiosos como batizados e primeira comunhão.

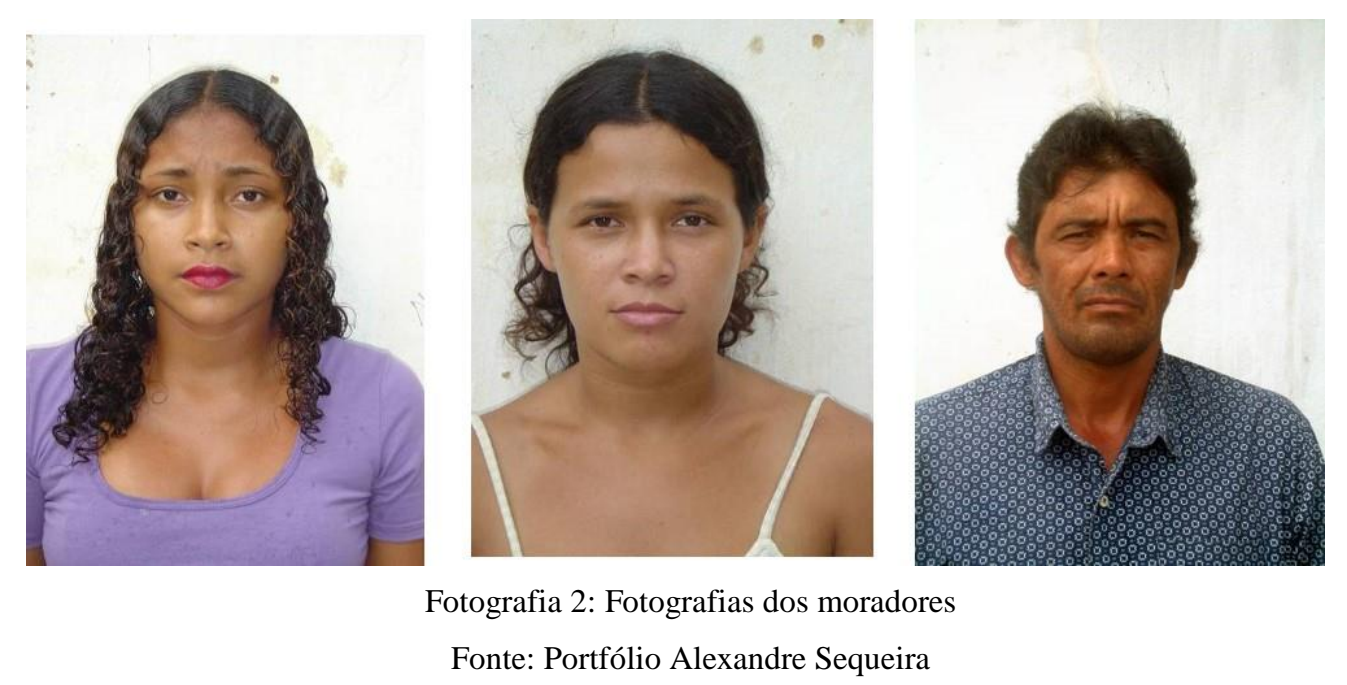

As fotografias realizadas eram reveladas e entregues sem custo aos moradores. Alexandre ia a Belém, revelava as imagens e realizava a entrega de forma coletiva na vila, com um varal, onde expunha as fotografias junto a um papel com o nome do solicitante. Mais de mil fotos foram produzidas e inseridas no cotidiano da vila, segundo dados do relatório final da pesquisa.

Essas não foram as primeiras fotografias a circularem pela vila, algumas pessoas já haviam fotografado na localidade. Havia fotos antigas que com o tempo e a alta umidade da Amazônia, vinham se desgastando. Aos poucos, alguns moradores mostraram essas fotografias a Alexandre com sentimento de pesar e ele se dispôs a recuperá-las. O processo era realizado através de softwares de edição de imagens e posteriormente ele entregava as fotografias recuperadas.

Um dado muito importante a ser considerado é que muitos moradores nunca tinham sido fotografados, atribuindo a esse momento um caráter diferenciado. Primeiro pelo ato em 
si, de ser fotografado, pois como afirma Sontag (2004, p. 21), "uma foto não é apenas o resultado de um encontro entre um evento e um fotógrafo; tirar fotos é um evento em si mesmo [...]". E segundo pela situação de se ver em uma fotografia impressa. A relação a ser estabelecida pelos moradores com as fotografias tende a ser de maior afeto e resguardo. A partir da intensificação e estreitamento da relação entre ele e os moradores, o artista passou a ser acolhido para dentro dos lares, com "conversa regada a café plantado, moído e torrado no lugar" (SEQUEIRA, 2005, p. 3). Assim, ele passou aos poucos a identificar o valor simbólico e afetivo que determinados objetos possuíam para seus donos. Nas casas havia cortinas, lençóis, toalhas de mesa, mosquiteiros, redes e então Alexandre percebeu que esses tecidos possuíam

elementos que traziam em sua materialidade o dado que faltava para se falar de uma relação: o tempo. O tempo que acolhe e rege os acontecimentos. Nos panos envelhecidos, cada desbotado, cada pequeno rasgado, era sinal de um momento vivido, signo que trazia a marca do tempo (SEQUEIRA, 2005, p. 4)

Continuando na perspectiva relacional de seu trabalho, o artista propôs a troca desses tecidos pessoais dos moradores por novos. Segundo Sequeira (2005, p. 4), a proposta foi recepcionada com surpresa e curiosidade, havia o interesse na troca de uma peça antiga por uma nova. $\mathrm{O}$ artista achou importante realizar um primeiro trabalho para os demais moradores entenderem a motivação para a troca, e para isto utilizou o lençol do menino Lucas.

Nos tecidos dos moradores, carregados de afeto e significação, foram impressas fotografias em tamanho real de seus respectivos donos. Para obter a altura das pessoas, Alexandre recorria à utilização de seu corpo como régua e comparava as alturas a partir de contato físico. As imagens foram então solarizadas e o fundo extraído em softwares de edição. A impressão nos tecidos foi realizada através da serigrafia, e para isso, a imagem foi transposta para fotolito, um filme transparente utilizado como matriz para impressão.

Com os tecidos prontos, Alexandre retornou a Mocajuba para entregá-los aos moradores. Os objetos não eram mais os mesmos, haviam sido ressignificados. O artista considera (PAINÉIS..., 2012) que a relação entre os moradores e seus respectivos tecidos "era uma relação linda porque não tinha nenhuma intermediação de algum julgamento técnico, [... ] era apenas uma relação direta com o seu duplo, com a sua imagem".

Em um primeiro momento realizou-se em Nazaré Mocajuba uma exposição com todos os tecidos. Posteriormente, os moradores os colocaram em suas residências, a maneira que melhor entendiam. (Fotografia 3) 
RELACult - Revista Latino-Americana de Estudos em Cultura e Sociedade

Revista Latinoamericana de Estudios en Cultura y Sociedad | Latin American Journal of Studies in Culture and Society

V. 03, ed. especial, ago., 2017, p. 65-79 | relacult.claec.org e-ISSN 2016/Atual: 2525-7870 | e-ISSN 2015/2016: 2447-018X

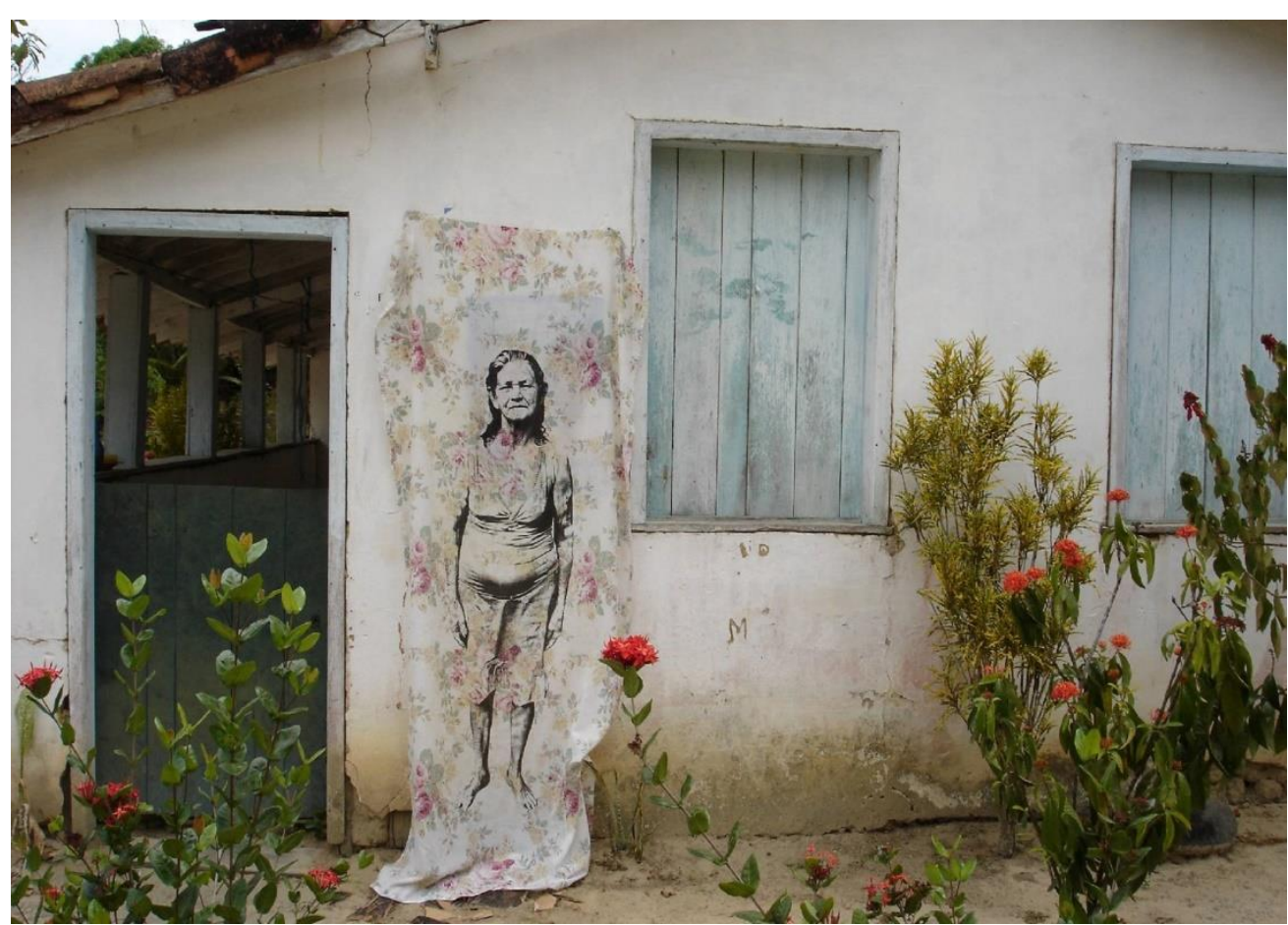

Fotografia 3: Branca

Fonte: Portfólio Alexandre Sequeira

A exposição seguiu para Belém e depois circulou o Brasil e o mundo, passando por países como Cuba, Estados Unidos, França, Inglaterra, Bélgica e Uruguai. Os tecidos não são comercializados, somente as fotografias da inserção dos tecidos nas casas, como a fotografia 3. O que é gerado por essa venda é repartido igualmente entre a vila e o artista. A exposição dos tecidos é uma das formas de apresentação do trabalho, assim como a oralidade, formato o qual Alexandre acredita que não seja apenas um relato da experiência em Mocajuba, e sim a própria obra. Portanto, há mais de uma forma de apresentação da série.

\subsection{Fotografia e memória na série Nazaré do Mocajuba}

Posto um breve panorama sobre a realização da série "Nazaré do Mocajuba", atentaremos agora nas discussões iniciais acerca das questões suscitadas por ela. É importante começar esclarecendo que o resultado da série não é puramente fotográfico. Ao ser transposta para os tecidos por meio da serigrafia, as fotografias passaram por transformações gerando um resultado híbrido. Portanto, serão abordadas aqui questões que envolvem não somente o resultado final, mas sim todo o processo.

Pensando nos tecidos, observa-se como o que foi gerado após a impressão das fotografias ressignificou o que antes eram peças comuns aos lares. Comum para quem é 
exterior ao local, pois como sinaliza Halbwachs (1990, p.131), "nosso entorno material leva ao mesmo tempo nossa marca e a dos outros". O autor complementa dizendo que os móveis e a casa em geral são organizados de uma forma que reporta a quem frequenta esse ambiente. Assim, aqueles objetos possuíam um significado para seus donos.

As marcas do tempo, já advindas nos tecidos, indicam diversos acontecimentos vividos. A impressão serigráfica das fotografias insere uma nova camada de significação e de aproximação dos objetos em relação aos seus donos. Alexandre comentou (ALEXANDRE SEQUEIRA..., 2010) que Dona Benedita ao observar sua imagem em seu tecido, ficou em silêncio e comentou que nunca imaginou que fosse tão parecida com sua cortina. A noção do duplo e da estranheza, que se deparar com a imagem duplicada de si pode proporcionar, é muito mais intensa nos tecidos do que nas fotografias.

Além disso, outro dado em relação aos tecidos é a reinserção deles nas casas dos moradores. Os próprios tiveram a liberdade de colocá-los nos lugares que gostariam. Nenhum dos tecidos retornou a sua função original. Em sua maioria foram expostos em paredes de diferentes cômodos da casa, como quadros, e também fora dela. O sentido de memória já implícito no objeto, foi reforçado e acrescido de lembranças não só pessoais, mas acredito que de todo convívio com Alexandre.

Nas fotografias tiradas no processo de produção da série, precisa-se reconhecer inicialmente o fato de que foram as primeiras fotografias de muitos dos moradores. Isso significa que a relação que eles vão estabelecer com aquelas imagens reveladas tende a ser mais intensa e menos banalizada. Ou seja, aquelas fotografias são únicas, colaborando para a construção de memória individual e coletiva, e por isso a atenção e o apreço pelas mesmas.

Diante, portanto, da oportunidade de ser fotografado, o que se deseja mostrar? Ser fotografado sozinho ou com quem se deseja estar? Em que lugar? Com que roupa? Com que expressão? Que imagem desejamos que fique preservada para as próximas gerações? É importante ponderar que a fotografia é produzida e construída, não sendo assim uma cópia da realidade. Faz parte de sua existência o cerimonial fotográfico, como Barthes (1984, p. 22) descreve que "a partir do momento que me sinto olhado pela objetiva, tudo muda: ponho-me a "posar", fabrico-me instantaneamente um outro corpo, metamorfoseio-me antecipadamente em imagem".

Ao observar e analisar as fotografias cedidas por Alexandre, que foram realizadas no processo de produção da série, observa-se diferentes cerimoniais, porém sempre associados a que imagem se deseja transmitir. Alexandre (2005, p. 2), que propunha não interferir na execução da fotografia, relata que "pessoas assumiam uma postura ereta e frontal com os 
RELACult - Revista Latino-Americana de Estudos em Cultura e Sociedade

Revista Latinoamericana de Estudios en Cultura y Sociedad | Latin American Journal of Studies in Culture and Society

V. 03, ed. especial, ago., 2017, p. 65-79| relacult.claec.org e-ISSN 2016/Atual: 2525-7870 | e-ISSN 2015/2016: 2447-018X

braços pendidos ao longo do corpo; pose solene, altiva, de um profundo respeito pelo momento do ato fotográfico". Essa atitude, concentrada e entregue ao momento, era conferida com maior frequência aos moradores antigos da vila (Fotografia 4).

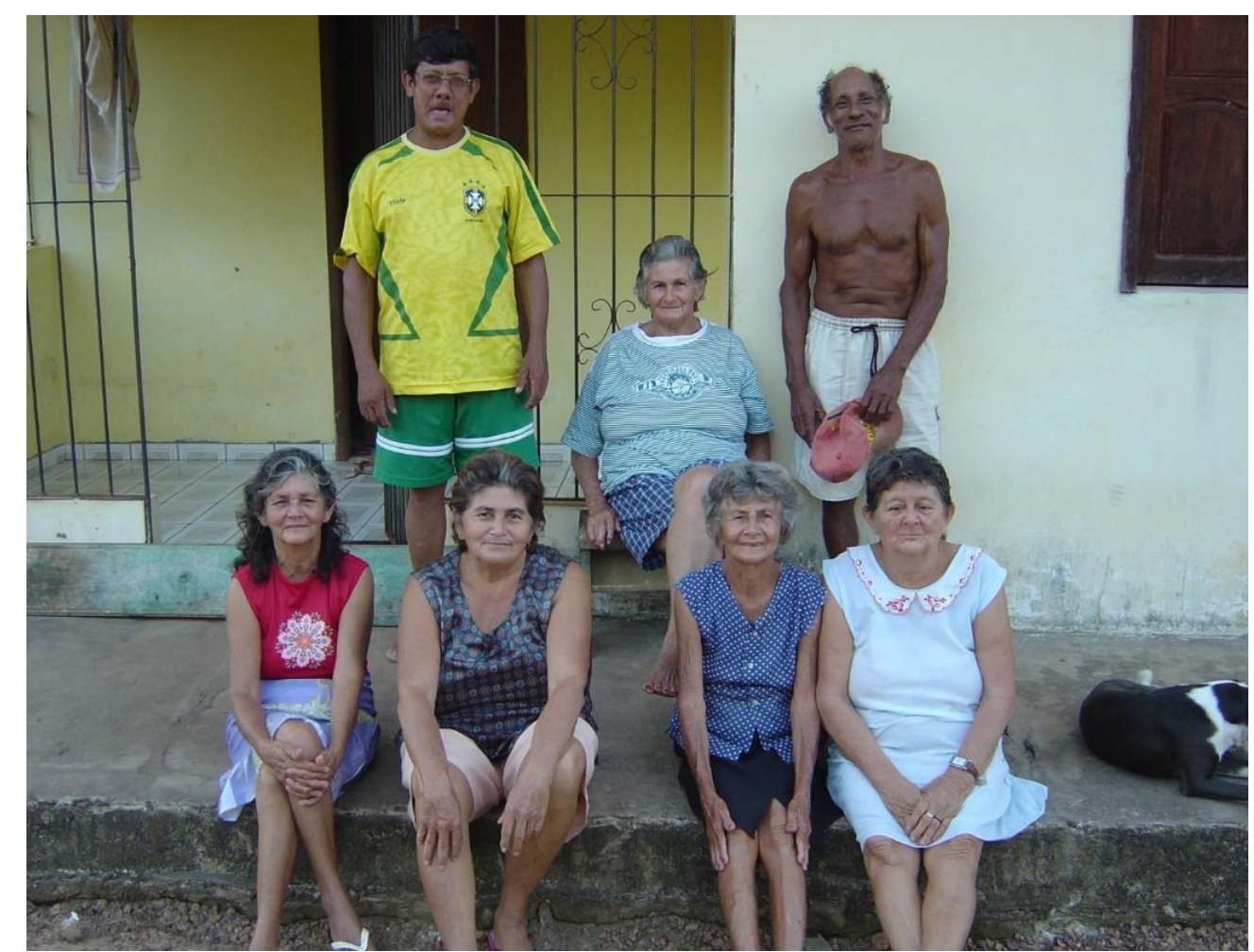

Fotografia 4: Cerimonial fotográfico 01

Fonte: Portfólio Alexandre Sequeira

Em relação aos mais jovens, conectados com as novidades da globalização, através do que era transmitido pela televisão, a atitude no ato fotográfico era diferente (Fotografia 5). Essa influência é conferida através da pose e do jogo de olhar, por exemplo. 
RELACult - Revista Latino-Americana de Estudos em Cultura e Sociedade

Revista Latinoamericana de Estudios en Cultura y Sociedad | Latin American Journal of Studies in Culture and Society

V. 03, ed. especial, ago., 2017, p. 65-79 | relacult.claec.org e-ISSN 2016/Atual: 2525-7870 | e-ISSN 2015/2016: 2447-018X

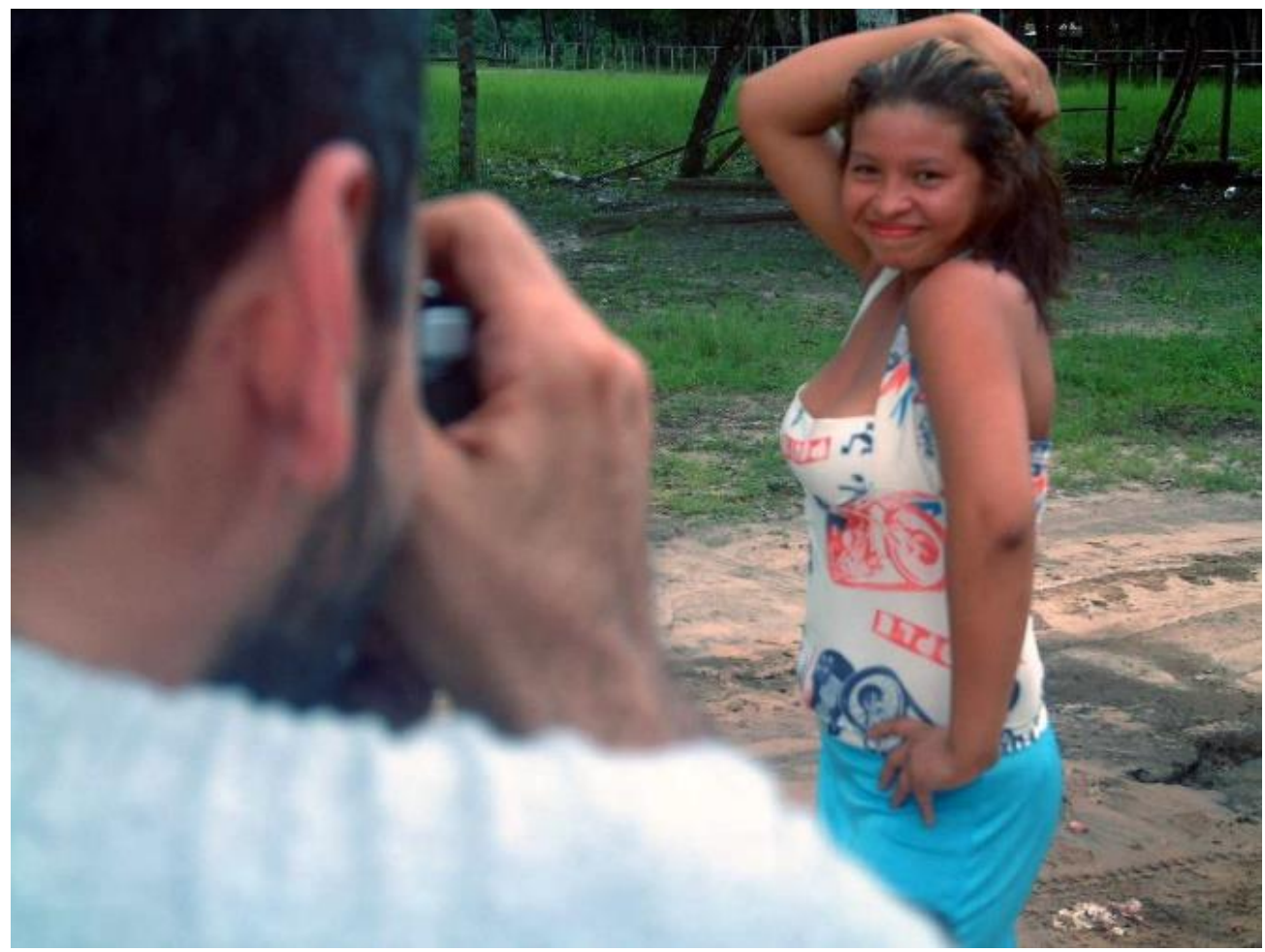

Fotografia 5: Cerimonial fotográfico 02

Fonte: Portfólio Alexandre Sequeira

As questões provocadas pelo cerimonial fotográfico, conectam-se ao conceito de identidade, intimamente ligado à memória. E tanto a memória quanto a identidade podem ser trabalhadas através da fotografia, sendo esta, suporte para a imagem que se deseja construir. Segundo Pollak (1992, p. 204),

podemos portando dizer que a memória é um elemento constituinte do sentimento de identidade, tanto individual como coletiva, na medida em que ela é também um fator extremamente importante do sentimento de continuidade e de coerência de uma pessoa ou de um grupo em sua reconstrução de si.

Para Felizardo e Samain (2007), a fotografia é justamente um dos melhores suportes porque aponta os caminhos da lembrança e, quando nos deparamos com a tentativa de rememoração de um acontecimento, são as imagens que vamos recorrer.

As relações entre fotografia e memória também são estabelecidas ao pensarmos no uso das fotografias reveladas. A significação do ato de guardar uma fotografia entre duas imagens de santos e envolta por um terço é forte (Fotografia 6). 

e-ISSN 2016/Atual: 2525-7870 | e-ISSN 2015/2016: 2447-018X

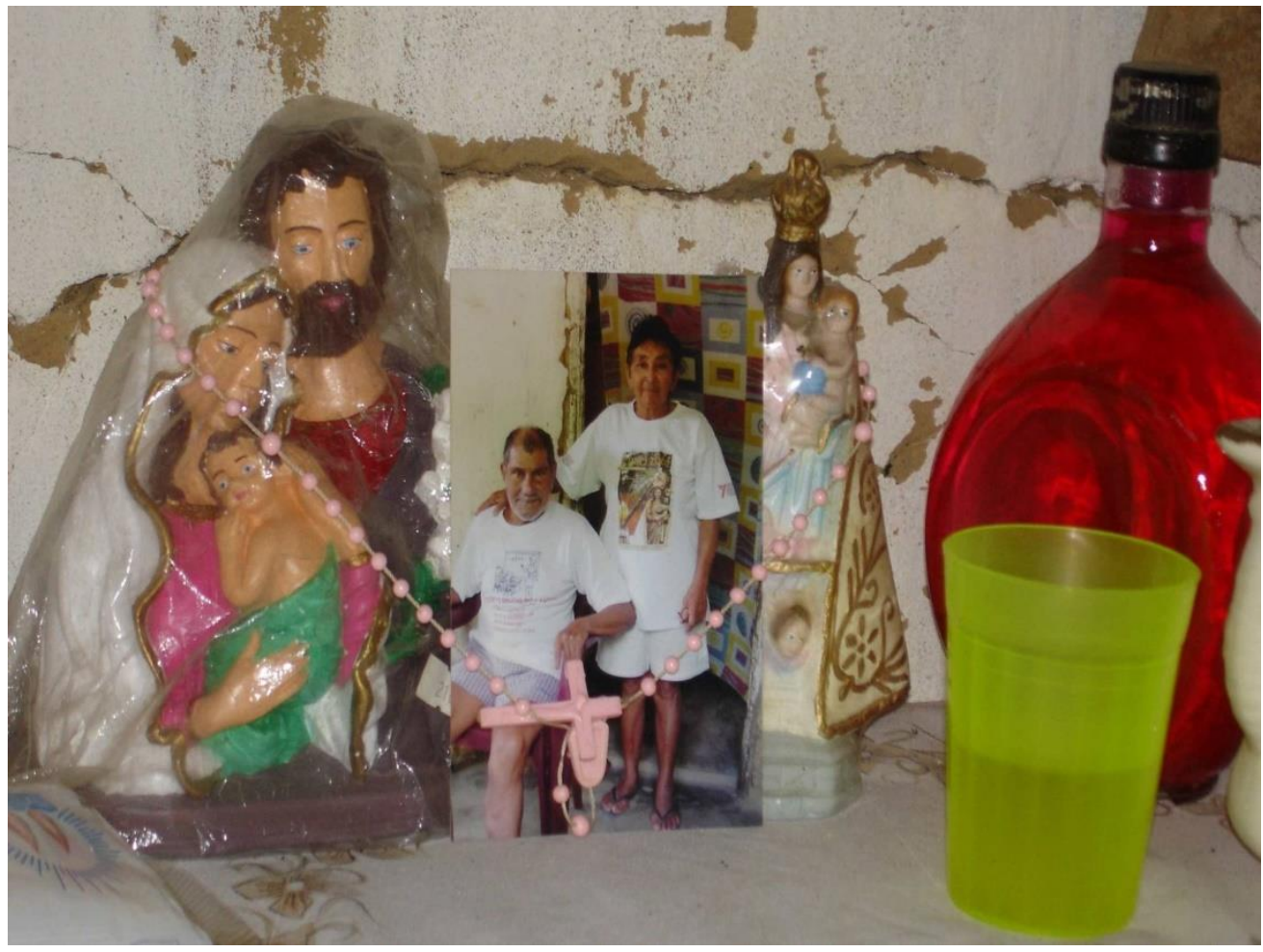

Fotografia 6: Fotografia no lugar do sagrado

Fonte: Portfólio Alexandre Sequeira

Todos os elementos religiosos citados referem-se ao sagrado. Ao mesmo tempo que a fotografia é preservada e protegida, ela é exposta a quem passar por aquele ambiente. Sobre a exposição das fotografias nas casas, Goveia e Zanotti (2008, p.5) afirmam que

O lugar de apresentação dessas cenas é o altar caseiro, um local de admiração, contemplação, rememoração. O sagrado mais uma vez se anuncia como parte inerente à fotografia em papel. A aura está no fato de uma imagem estar impressa e disponível para o olhar íntimo da sala de estar.

A bíblia também foi um local utilizado para guardar fotografias realizadas por Alexandre. O cuidado e a relação que demonstram possuir com essas imagens, denotam a valorização daquele registro, da possibilidade de guardar essa lembrança. Pois como afirma Halbwachs (1990, p. 143) "[...] não seria possível compreender que pudéssemos recuperar o passado, se ele não se conservasse, com efeito, no meio material que nos cerca."

Portanto, pode-se considerar que as fotografias realizadas por Alexandre são lugares de memória. Segundo Nora (1993, p.13), os lugares de memória "nascem e vivem do sentimento que não há memória espontânea, que é preciso criar arquivos, que é preciso manter aniversários, organizar celebrações [...]”. A razão da existência dos lugares de memória é de impossibilitar o processo de esquecimento e para sê-lo, é necessário haver a 
vontade de ser memória e estar imbuído de uma aura simbólica, assim como observou-se com as fotografias.

\section{Conclusões}

O encontro de Alexandre com a vila de Mocajuba e seus moradores permitiu não só a criação de novas memórias, individuais e coletivas, como a recuperação de outras. A relação entre fotografia e memória é estabelecida em todo o ato fotográfico.

Mais de 10 anos após realização da série, a memória da cidade e dos moradores, perdura viva e em constante revisitação, tanto pelas pessoas que observam o trabalho em exposições e pela internet, quanto pelos moradores e ex-moradores. Em um comentário no site de Alexandre, realizado em janeiro de 2011, um nativo da localidade afirma navegar sempre pelo site do artista para rever fotos de seus parentes.

Percebemos assim, como esse trabalho afeta a outras pessoas e gerações, para além daquelas que tiveram contato com Alexandre e seus tecidos ressignificados. As fotografias permitiram e permitirão a rememoração de pessoas, lugares e momentos. Alexandre Sequeira, ao viver e conviver com os moradores de Nazaré do Mocajuba e ter um trabalho artístico suscitado desse encontro, abre caminhos para a construção, por parte dos moradores, de suas memórias individuais e coletivas, agora acrescidas de fotografias.

\section{Referências}

ALEXANDRE SEQUEIRA reencontra o sentido da fotografia. TEDxAmazônia, novembro 2010. Disponível em https://www.youtube.com/watch?v=Do2HhRQhQRM. Acesso em: 20 ago. 2016.

BARTHES, Roland. A câmara clara: nota sobre fotografia. Rio de Janeiro: Nova Fronteira, 1984.

BORRIAUD, Nicolas. Estética relacional. São Paulo: Martins, 2009.

BRASIL, Luísa Kuhl. Do ateliê para as 'belas artes': relações entre fotografia e arte no início do século XX. In: ENCONTRO ESTADUAL DE HISTÓRIA - História, memória e patrimônio, 11., 2012, Rio Grande. Anais... Rio Grande, 2012.

FELIZARDO, Adair; SAMAIN, Etienne. A fotografia como objeto e recurso de memória. Discursos fotográficos, Londrina, v.3, n.3, p.205-220, 2007. Disponível em http://www.uel.br/revistas/uel/index.php/discursosfotograficos/article/view/1500 . Acesso em 16 nov. 2016

FERNANDES JUNIOR, Rubens. Processos de criação na fotografia: apontamentos para o entendimento dos vetores e das variáveis da produção fotográfica. FACOM. São Paulo, n. 16, p. 10-19, 2006. Disponível em: 
http://www.faap.br/revista_faap/revista_facom/facom_16/rubens.pdf. Acesso em: 12 set. 2016.

GOVEIA, Fabio; ZANOTTI, Rosane. Memória Privada e Memória Coletiva na Fotografia Contemporânea. In: CONGRESSO BRASILEIRO DE CIÊNCIAS DA COMUNICAÇÃO, 31., 2008, Natal. Anais... Natal, 2008.

HALBWACHS, Maurice. A memória coletiva. São Paulo: Vértice, 1990.

LE GOFF, Jacques. História e memória. Campinas, SP: Ed. Unicamp, 1990.

MACHADO, Vânia Leite Leal. Nazaré de Mocajuba-PA: matriz inspiradora na fotografia de Alexandre Sequeira. 2011. 112f. Dissertação (Mestrado em Comunicação, Linguagens e Arte) - Universidade da Amazônia, Belém. 2011

NORA, Pierre. Entre a memória e a história: a problemática dos lugares. Projeto História, no 10, p. 7-28, 1993.

PAINÉIS, do evento Pensamentos e Ações - Seminário Internacional de Cultura e Formação. Itaú Cultural, São Paulo, 2012. Disponível em https://www.youtube.com/watch?v=Z1ZOigbv52o . Acesso em 17 set. 2016.

POLLACK, Michael. Memória e identidade social. Revista Estudos Históricos, Rio de Janeiro, v.5, n.10, p.200-212, 1992.

ROUILLÉ, André. A fotografia: entre documento e arte contemporânea. São Paulo: Editora Senac, 2009.

SEQUEIRA, Alexandre. Relatório Final da Pesquisa. Belém: IAP, 2005.

SOBRAL, Armando. Impressões de um lugar. Disponível em: https://armandosobral.wordpress.com/category/impressoes-de-um-lugar/ . Acesso em: 20 dez. 2016

SONTAG, Susan. Sobre Fotografia. São Paulo: Companhia das Letras, 2004.

TAKAMI, M. C.. Fotografia na História da Arte. In: II ENCONTRO DE HISTÓRIA DA ARTE, 2006, Campinas. Anais... Campinas, 2006. 